2003-9

\title{
Institutional Issues in the Implementation of an International Student Exchange Program
}

\author{
Mary E. Duffy \\ University of Utah \\ Suzette Farmer \\ University of Utah \\ Patricia K. Ravert \\ Brigham Young University - Provo, patricia-ravert@byu.edu \\ Liisa Huittinen \\ Mikkeli University of Applied Sciences
}

Follow this and additional works at: https://scholarsarchive.byu.edu/facpub

Part of the Other Nursing Commons

\section{Original Publication Citation}

Duffy, M. E., Farmer, S., Ravert, P., \& Huittinen, L. (2003). Institutional Issues in the Implementation of an International Student Exchange Program. Journal of Nursing Education. 42(9), 399-405.

\section{BYU ScholarsArchive Citation}

Duffy, Mary E.; Farmer, Suzette; Ravert, Patricia K.; and Huittinen, Liisa, "Institutional Issues in the Implementation of an International Student Exchange Program" (2003). Faculty Publications. 5266. https://scholarsarchive.byu.edu/facpub/5266 accepted for inclusion in Faculty Publications by an authorized administrator of BYU ScholarsArchive. For more information, please contact ellen_amatangelo@byu.edu. 


\section{Institutional Issues in the Implementation of an International Student Exchange Program}

Mary E. Duffy, PhD, RN; Suzette Farmer, MS, RN; Patricia Ravert, MS, RN; and Liisa Huittinen, MS, RN

\begin{abstract}
This article discusses institutional issues related to the development and implementation of an undergraduate student exchange program in nursing. A consortium of four universities in the United States and six nursing schools in three European countries developed an exchange program to teach a common community health module. Thirty-one students from the United States and 30 students from Europe participated in this program, which was funded by the U.S. Department of Education and the European Union. The project commenced with a 3 -week meeting of faculty and students to design the 8week exchange program and cultural preparation module. This article describes institutional issues related to the project. Academic issues, nonacademic issues, and exchange procedures are presented. The extended meeting of faculty and students that occurred early in the funding period was critical to this program's success.
\end{abstract}

\footnotetext{
Received: February 6, 2002

Accepted: October 15, 2002

Dr. Duffy is Professor, and Ms. Farmer and Ms. Ravert are doctoral students, University of Utah, College of Nursing, Salt Lake City, Utah; and Ms. Huittinen is Senior Lecturer, Mikkeli Polytechnic, Savonlinna, Finland.

The authors wish to thank the faculty, students, and staff from each of the participating universities in Finland, Northern Ireland, Portugal, and the United States for their contributions to the success of this project. The authors also acknowledge funding from the U.S. Department of Education's Fund for the Improvement of Postsecondary Education (FIPSE) Program and the European Union.

Address correspondence to Mary E. Duffy, PhD, RN, Professor, University of Utah, College of Nursing, 10 South 2000 East Front Street, Salt Lake City, UT 84112; e-mail: mary.duffy@nurs.utah.edu.
}

$\mathrm{U}$ niversities have recognized the benefits of international education for students and have increased its emphasis in curricula. However, the primary beneficiaries have been students from foreign countries whose numbers have increased at U.S. universities. Less than $10 \%$ of U.S. students study in a host country (Davis, 1999; Wheeler, 2000). Cost, difficulties with transferring credits, lack of language skills, requirements of the major, other personal demands, and ethnocentrism keep students at home (Akande \& Slawson, 2000; Bachner, 2000).

These common barriers are cited in nursing. In an attempt to encourage transatlantic education in many disciplines, the U.S. Department of Education, through the Fund for the Improvement of Postsecondary Education (FIPSE), and the European Union (EU) established a joint program (FIPSE-EU) designed to tackle these issues. A consortium of nursing schools from the United States and Europe were awarded funding to develop an international community health assessment and planning module and to enhance cultural education. This article describes the international exchange program and reports the outcome data at the institutional level.

\section{LITERATURE REVIEW}

Former U.S. President Clinton issued a proclamation in 2000:

Today we live in a global community, where all countries must work as partners to promote peace and prosperity and to resolve international problems. One of the surest ways to develop and strengthen such partnerships is through international education programs. (p. 2868)

Clearly, in the age of diffuse international boundaries, open travel, ease of communication, evolving trade policy, and global economy, educated individuals would be well advised to learn about other cultures and incorporate this knowledge into their daily work and lives. In 2000, the 
National League for Nursing issued a report that identified globalization of the world's economy and society as significant to nursing education (Heller, Oros, \& DurneyCrowley, 2000). The report urged nurse educators and researchers to become more internationally focused and to benefit from multicultural experiences.

Many nursing administrators and faculty perceive the demands of undergraduate education as barriers to student exchanges. The pressure to teach students an expanding body of knowledge in a restricted time frame reinforces the need to control the educational experience. The student exchange program requires faculty to relinquish responsibility for teaching part of the curriculum to host faculty (Duffy, Harju, Huittinen, \& Trayner, 1999). Openness, flexibility, trust, and collaboration are inherent in the development and implementation of international education.

\section{Models of International Education}

International education is either unilateral or collaborative. Unilateral models include education of foreign nationals in preparation for registration and advanced degree and study travel to a host institution by a group of students and home faculty (Cummings, 1998; Inglis, Rolls, \& Kristy, 1998; Ryan, Markowski, Ura, \& LiuChiang, 1998; Scully, Birchfield, \& Munro, 1998; Stevens, 1998). Three collaborative models are found in the literature:

- Technology exchanges (Iwasiw et al., 2000; Kim \& Vetter, 1999; Kirkpatrick \& Brown, 1999).

- Study abroad (i.e., the exchange of groups of students and home faculty between two countries) (Gallicchio, Kirk, \& Birch, 1998; Goldberg \& Brancato, 1998; Kraemer, 1998).

- Student exchange, which is the focus of this article.

Student exchange is the most challenging model. Students leave their home school during the academic term and study at a host institution under the direction of the host faculty. Visiting students are enrolled in and receive credit for course content required by the home institution's curriculum (Duffy et al., 1999). This model is common in disciplines other than nursing. In a review of current research, Bachner (2000) found that the academic experience should be woven into the home curriculum and at a minimum be credit bearing. Students need systematic orientation to the host country, logistical and advisory support before and after the experience, and systematic debriefing on return to increase integration of the experience into their personal and professional lives. A constant challenge is to provide financial assistance to broaden the population of students able to participate.

The difficulties of the student exchange model are acute in a practice profession. Language barriers, variable access to technology, and inadequate preparation for and synthesis of the international education experience are complicated further by personal problems (Cummings, 1998; Gallicchio et al., 1998; Goldberg \& Brancato, 1998; Kim \& Vetter, 1999; Kraemer, 1998;
Scully et al., 1998; Stevens, 1998). Cultural differences abound and are reflected in the health care delivery systems, expectations of nurses, and decision-making processes (Goldberg \& Brancato, 1998; Scully et al., 1998).

However, the arguments for international education in nursing continue to grow. Identifiable changes in the level of awareness of health care and health (Rolls, Inglis, \& Kristy, 1997), positive changes in cognitive development (Zorn, Ponick, \& Peck, 1995), and effective learning outcomes for baccalaureate nursing students have been demonstrated (Haloburdo \& Thompson, 1998). Researchers in a follow-up study of alumni of the Institute for International Education of Students reported that individuals with an experience in international education have greater likelihood of continuing an international component in their lives through employment, volunteerism, support of international education, or encouragement of children or grandchildren to study in a foreign country (Akande \& Slawson, 2000).

\section{Exchange Preparation}

Adequate preparation for student exchange is essential. Ideally, students will speak the language of the host country. Realistically, language preparation in nursing ranges from crash courses supplemented by an onsite dictionary (Stevens, 1998) to use of interpreters (Kim \& Vetter, 1999; Stevens, 1998). With little exception, U.S. nursing students require host faculty who speak and teach in English.

Cultural preparation is required. Preparation for an international experience typically includes personal reflection on and education about the history, culture, and nursing roles of the host country (Cummings, 1998; Goldberg \& Brancato, 1998; Kim \& Vetter, 1999; Kraemer, 1998; Scully et al., 1998; Stevens, 1998). In addition, students need the skills to critically reflect on what they are experiencing professionally and personally (Duffy, 2001). Throughout the process, faculty should challenge students' stereotypes and generalizations, encouraging development of a new understanding (Hannerz 1996; Mohr \& Naylor, 1999).

Despite preparation for study abroad, individual problems do occur and can be diagnosed by analyzing the location of the problem (Bachner 2000). Problems within individuals are seen across home and host settings, problems in the setting are unique events in the host country, and problems of intercultural adjustment are experienced in the host setting but not on return.

The student exchange program described in this article used participatory action research to develop the exchange and the common module offered by a consortium of European and U.S. nursing schools. Institutional issues and faculty relationships are presented for the consortium. Student perceptions are limited to U.S. students because of the many issues of culture, education, and previous experience that affect students' perceptions of study in a foreign country. 


\section{METHOD}

The program described in this article evolved from an exchange program in community health nursing developed by faculty from three of the participating schools (Duffy et al., 1999). The expanded consortium of schools from Finland, Northern Ireland, Portugal, and the United States used the knowledge from this experience to implement a project funded by FIPSE-EU. The systems-level objectives were to:

- Increase access to cross-cultural education for students and faculty.

- Expand access to international education for disadvantaged students.

- Develop internationally appropriate curriculum materials to increase knowledge and skill in culturally sensitive community assessment and planning.

Participatory action research was selected because it is a practical research approach that allows participants to continually assess the environment and change practice (Grady, 1998; McNiff, Lomax, \& Whitehead, 1996; Mills, 2000). Action researchers describe, interpret, and explain, while seeking to change practice (McNiff et al., 1996). Research to assess the efficacy of the project provides data for reflection and change throughout the project. This dynamic process, which is dependent on a reflective spiral of action and research, is suitable for evolving projects, such as an international educational exchange module. Prior to receiving funding, only a subgroup of principle consortium members had met in person, and most members were brought in one time to write the grant. After funding was received, the consortium members (i.e., students and faculty) came together to design the structure of the project, while allowing each institution the flexibility to adapt the structure to their setting.

The grant funded creation of viable structures at each institution to promote international student exchanges. Therefore, the research questions focused on the feasibility of each institution to meet the project objectives. An independent team developed the evaluation plan and participated in its implementation. The evaluation plan was presented and discussed at the first meeting.

\section{Project Overview}

Four U.S. and six European nursing programs from three countries participated in this project. The four universities are located in diverse geographical areas of the United States (i.e., Boston, Massachusetts; Washburn, Kansas; Salt Lake City, Utah; and San Antonio, Texas). Although e-mail was the primary method of communication, faculty did meet once or twice per year to evaluate progress and alter practice. The first major event was a 3week meeting in Portugal for the faculty and student leaders. The purposes of the meeting were to:

- Acquaint faculty and students with each other and the project.

- Build a common international community health module.
- Organize the logistics of preparing, exchanging, and teaching students.

Student leaders were selected from each university to participate in the planning and implementation of the project, beginning with the meeting in Portugal. They helped design the educational materials, plan the logistics, and recruit classmates for the 8-week exchange program planned for the next year.

In the second year, the student exchange was implemented. Each university developed its own selection criteria. Preparation for study abroad, language instruction, and cultural education occurred the semester before the exchange. In the third year of the grant, an interdisciplinary conference on international education was held in Finland. The participating programs sponsored the conference and presented their experiences.

\section{Data Collection and Analysis}

Process and outcome data identified in the research plan were collected throughout the project and 2 years after the student exchange occurred. Surveys on cultural and community health education outcomes were completed at the beginning and conclusion of the exchange by participating students and their classmates who remained in the United States. Unfortunately, these data were incomplete and unable to be analyzed. Interviews with students who participated in the exchange and student leaders were completed and used to recommend changes in the project. Data from student leaders were important to the design of the exchange and were presented for discussion at the faculty meetings in the second and third years. Interview data from the students who completed the exchange were analyzed and used during the third year faculty meeting to redevelop the structure of the exchange program. In this article, general program data from faculty work meetings, student interviews, and findings of two instruments are reported.

Core faculty completed the consortium Team Member Survey (Kumpfer \& Hopkins, 1993) at the end of the first year and 1 year after the project was completed. The instrument measures the internal processes and group climate of the consortium and can be linked to effectiveness outcomes (Kumpfer, Turner, Hopkins, \& Librett, 1993). The survey has five subscales (i.e., expectations; knowledge, skills, and beliefs; decision making; community links; and satisfaction) and three open-ended questions that ask respondents what was worthwhile, what was not worthwhile, and what respondents would like to change regarding participation in the consortium. The Team Member Survey data were analyzed by comparing group means on the subscales. Changes in personnel did not allow comparisons among individual surveys.

Students were asked to respond by telephone or e-mail to an open-ended interview conducted by a doctoral student 2 years after the completion of the exchange. In addition to demographic data, participants were asked:

- Whether they would recommend the program to future students. 
- To identify the strengths of the program and problems encountered.

- To describe their recommendations for future implementation of the program.

One faculty member and two doctoral students analyzed the interviews. The faculty member and doctoral student who did not conduct the interviews independently analyzed a sample of interviews. A meeting then was held with the doctoral student who conducted and analyzed the interviews. Both analyses were compared, and the next step in the analyses was planned. Meetings and subsequent analyses were conducted until categories were developed. The small number of interviews and structured data allowed this team of three to stay actively involved in the analysis throughout the process. Analyses were completed specific to home and host institutions and student travel experiences.

\section{RESULTS}

Nine faculty responded to the Team Member Survey at the end of the first year, and 11 faculty responded 1 year after completion of the project. Responses were received primarily from the project leaders at each school. The majority of faculty leaders and participants taught undergraduate community health nursing. Group means of the consortium members changed only slightly from the first year to 1 year postproject. The subscales of knowledge, skills, and beliefs and decision making increased slightly, indicating an improvement but not a significant change. Knowledge, skills, and beliefs were specific to cultural understanding, interaction, and sensitivity. Decision making assessed the level of democracy among group members and the leader.

Thirty-one U.S. students participated directly in this program by one of two activities. Four students traveled with faculty for the short-term course in Portugal and continued participation in the program at their home institution. The remaining 27 students studied for 8 weeks at one of six nursing programs in three European countries. A quarter of the participants (25.8\%) were considered disadvantaged students, based on federal financial or ethnic/racial criteria. They represented $29.6 \%$ of the 27 students who participated in the 8-week exchange.

Twenty-one students $(67.7 \%)$ completed the survey 2 years after project completion. Of these students, 19 were ages 20 to 29 and 2 were ages 30 to 39 . All of the graduates were employed in nursing, with 17 (80.9\%) working in acute care and $4(19.0 \%)$ working in community settings. Seven students $(33.3 \%)$ had participated in an earlier exchange program or lived outside the United States for more than 6 months, while 3 (14.3\%) had never traveled outside the United States.

Overall, the program was a success and recommended for future students. Students expressed enthusiasm for the program regardless of previous travel experience or their home or host institution. Their support was unanimous. Comments included:
- Awesome learning experience.

- With whatever means possible, students should participate.

- Wonderful!!! It was one of the best experiences of my life! It greatly enhanced my undergraduate experience!

- Overall, it was the best thing I have done for myself. The memories and experiences have changed my views, thoughts and the person that I am.

\section{Increase Access to Cross-Cultural Education for Students and Faculty}

Faculty access to cross-cultural education was enhanced during the 3 -week meeting in Portugal. The majority of faculty had never participated in a student exchange program and were concerned about students learning required course content taught by host faculty. Faculty described the process of developing trust in each other and the project goals as:

- Establishing ties with schools and faculty in the United States and European Union.

- Working alongside international colleagues.

- Sharing ideas and expertise and making the "impossible" work.

- Knowing that international exchanges in nursing studies can be done.

This initial extended meeting allowed trust to develop. Faculty from the United States and Europe were surprised to find more similarities than differences in their curricula and course content. The trusting relationship that developed among faculty during professional activities and social events allowed common course planning to occur. By the end of the meeting, faculty were committed to the exchange and prepared to promote the idea among their home faculty. Trust was a prerequisite to planning the exchange. After trust was developed, the focus of interaction changed from "Should or can we do an exchange?" to "How do we accomplish an exchange?"

Access to cross-cultural education for students and faculty was increased by the presence of the exchange students from Europe and the interaction of faculty and students both during and after the exchange. Communication with U.S. students studying in Europe occurred during the exchange. E-mails about differences in health care often were shared with the students' classmates for discussion. On return to their home institutions, students made presentations in the classroom, the home department, and at work; wrote articles for department and university newsletters; and shared informally with classmates, faculty, and colleagues who had stayed at home.

One faculty member thought the most worthwhile outcome of the project was "Working with different cultures and learning to appreciate their differences." Students echoed the value of this experience as cultural education and commented that their learning included:

- How to not view the world through an Americanized lens.

- Learning through negotiation and to see other points of view. 
- To be more open minded when it comes to other cultures and especially, health care practices.

- The difficulties of being a 'foreigner' (i.e., language barriers) not being able to read directions, menus, bus schedules, etc.

\section{Develop Internationally Appropriate Curriculum Materials}

An international module for teaching community health assessment and planning was developed. The critical components of the module were outlined in Portugal during meetings with students and faculty. The student leaders were an integral component of all planning that occurred in Portugal and continued to participate at the home institution.

The common module included health policy, policy empowerment, health care system and finances, descriptive epidemiology, public health movements and projects, health education, and the care of aggregates and groups. Each university adapted the module to fit their schedule and course content. The common activity was a community assessment and plan completed by student teams representing the various nursing programs and countries.

The second curriculum issue was the cultural preparation course schedule for the semester prior to the exchange. Cultural education included language instruction, as needed, and topics such as geographic setting; historical roots; politics; natural resources; economics; food preferences; art forms; folk tales and stories; myths, symbols, and rituals; and community health care services. Each institution developed its own cultural education program and their participation in each of the common elements varied. Problems arose when universities had difficulty recruiting students with sufficient time for cultural preparation. A faculty member summarized the problem, saying "[We] Would not have extended deadlines for exchange applicants. We did not have enough time to prepare our students."

The authors' university developed a 2-credit hour required cultural preparation course that continues today. Students discuss their own culture and health care delivery system, as well as those of the host country. Often there are students from the host country enrolled in this preparation course with the U.S. students. The host country students can provide information and understanding about the host culture, as well as challenge the U.S. students on issues related to American culture and health care. The discussions can be lively.

\section{Issues}

Bachner (2000) found that problems arise from the person, setting, and intercultural adjustment. Problems of the setting (i.e., home or host institutions) will be discussed in this article because the focus is on evaluation of the institution.

One of the four U.S. universities had prior experience with student exchange. Therefore, the other universities had to develop the infrastructure necessary to send and receive exchange students. Issues included:

- Academic issues related to grading and credits, placement of the course in the academic schedule to avoid repetition, other course requirements to assure progression, challenges of an integrated curriculum, matching academic schedules with the host institution and the other U.S. universities sending students to the same host institution, student recruitment, and faculty experience working with home students at a remote location.

- Nonacademic issues related to housing for visiting students, integrating students into the host academic environment, and managing daily living.

- Exchange procedure issues related to the application process, development of a process of academic exchange that allows students visiting U.S. universities to register for the duration of the exchange without paying tuition and with all of the privileges of full-time students, and institutional contracts addressing issues of liability and insurance.

Academic Issues. Students were concerned about academic requirements from their home institution; timing of the exchange in the curriculum; language difficulties; the hours of academic work required in the host institution, including attendance in classes and clinical experiences; communication with home faculty; and integration of foreign study into the requirements of the home institution. These problems occurred in various degrees across institutions, reflecting institutional problems and individual student perceptions. As stated above, this exchange was a new experience for three of the four U.S. universities. Issues such as workload, timing of the exchange in the curriculum, and integration of foreign study need experience and time to be addressed adequately.

Although students were not employed while in the host country, the time requirements were much greater than they expected. Most students had some requirements to complete at the home institution to progress with their classmates. These students perceived a double burden because they were surprised at how many hours of classroom contact and clinical experience European students are required to fulfill. The U.S. students often expected the structure of the academic week would resemble that of their home university, but it did not. Some host institutions required 37.5 hours of clinical experience per week, and others required up to 40 hours of classroom contact per week.

Communication problems occurred between the students and the home institution. One student expressed succinctly the concerns of several participants by saying, "[We] Need clear cut expectations and good communication with home faculty." The language of the host country must be considered in planning exchanges and student preparation. Although language difficulties were an immediate barrier for some students, this difficulty provided an important lesson in the need for translators. One student who was frustrated with the language difficulties discussed its effect on her professional practice. She said, 
"I am more concerned about the patients who don't speak the language and always get translators."

Nonacademic Issues. The nonacademic issues were setting specific. In general, students felt warmly received and believed housing and other essentials of daily living were well organized in the host country. There was one host institution about which students from three U.S. universities expressed similar complaints. They reported that no one from the institution met them at the airport, they were alone on campus, and they failed to receive general directions and information on day-to-day events. Initially, the students were frustrated, and many were ready to go home. They labeled the structure as disorganized. However, the host faculty had a different perception. They described the students' request for structure as "pastoral care," or a need to be nurtured. Clearly, a cultural difference existed between the U.S. students' and host faculty's perceptions of faculty's role. Interestingly, two students from this host institution studied in the U.S. These students complained that university faculty and local individuals were too nurturing, too available, and too involved in their lives. They wanted to be left alone.

Exchange Procedure Issues. The grant required that all students pay tuition at their home institution and be guaranteed the benefits of full-time students at the host institution. Some of the U.S. universities had these procedures in place and nursing programs could access them. Other universities had to develop procedures. One university complied with the grant requirements for the exchange period but was unable to continue participation in the project because of the rigidity of their system. The university with exchange experience was able to share their contract for use with host institutions and their expertise. The contract addressed issues of liability insurance, housing, responsibilities, and tuition exchange. Significant funding for student travel was provided through the grant. Therefore, cost of the experience was a minimal issue.

The primary faculty complaint was insufficient time for the project. Comments included, "Redistribution of workload-recognize the work involved in participation," and "The leader would have more time for working in the project and the site coordinators as well."

\section{DISCUSSION}

Students from the United States embraced the opportunity to study in another country. The number of participating U.S. and European students was equal during the grant. Outside the grant period, the number of U.S. students willing to subsidize their international exchange has exceeded their European peers. This pattern is not evident in other disciplines. However, changes in world stability since the terrorist attacks of September 11, 2001 have affected some students' willingness to participate in international exchange.

The greater issue for development of exchange programs is faculty's commitment to international exchange.
The number of U.S. faculty-led study abroad programs continues to increase, but development of student exchange programs is far less common. Requirements of the major, curriculum equivalency, and the ability of the host faculty to teach required course content restrain exchange program development. Peterson (2000) identified faculty as the key component to institutionalizing international education and increasing the number of students who study abroad. However, U.S. faculty, compared to their foreign colleagues, have limited experiences in other countries (e.g., sabbaticals) and place less value on scholarly work produced outside the United States (Altbach, 1996; Petersen, 2000). Ethnocentrism affects the attitudes and worth placed on international education.

Faculty participating in this project worked well together. The Team Member Survey indicated stability and growth in all aspects of group process. Unfortunately, the survey was not administered prior to the initial meeting of the consortium so meaningful comparisons could be made during and after the project. The 3-week consortium meeting in Portugal during the first year was critical to this project's success. In general, greater attention should be paid to evaluation. A significant research plan was developed by independent researchers, but greater attention needed to be paid to the cultural issues that determined its implementation. The plan was ambitious and, in keeping with action research, needed to be adapted. In the future, an independent team of researchers representing each country should convene to design and implement the research plan. Fortunately, sufficient data were collected to analyze team building among faculty and the implementation of the project at the institutional level.

The project was a success because the systems-level objectives of increased access to cross-cultural education for students and faculty, expanded access to international education for disadvantaged students, and development of internationally appropriate curriculum materials to increase knowledge and skills in culturally sensitive community assessment and planning were met. Despite the project's success, many issues are left for further development. Issues related to contracts, exchange agreements, home university requirements, and faculty-student communication can be addressed if universities and faculty are flexible and willing to adapt. Sample contracts and exchange agreements are readily available to share among universities. Curriculum issues depend on faculty's trust of peers in the host institution and flexibility.

\section{CONCLUSION}

Cultural education is the centerpiece of international education. In this study, both students and faculty reported personal and professional growth, including keeping an open mind to the way things are done in other countries. The community health module facilitated discussion of comparative health systems, and living in another 
country raised issues related to daily life. Previous travel experiences and personalities influenced individual responses. The challenge for faculty is to develop effective educational strategies to facilitate critical reflection by students on their experiences and to develop new understandings (Duffy, 2001; Hannerz, 1996; Mohr \& Naylor, 1999). Students need guidance as they move away from stereotypes and generalizations based on the familiar (i.e., their own culture). The comments of one student reflect the program's goal to increase the number of graduates who work sensitively with people from other cultures both domestically and internationally:

It confirmed my desire to continue to work with medically underserved populations, to continue in international medicine and nursing practices, and to continue to explore the diversity and contributions of differing cultures in medicine.

\section{REFERENCES}

Akande, Y., \& Slawson, C. (2000). A case study of 50 years of study abroad alumni. International Educator, 9(3), 12-17.

Altbach, P.G. (Ed.). (1996). The international academic profession: Portraits of fourteen countries. Princeton, NJ: The Carnegie Foundation for the Advancement of Teaching.

Bachner, D. (2000). Study abroad: A summary. AAC\&U Peer Review, 3(1), 8-12.

Clinton, W.J. (2000). Proclamation 7376: International education week, 2000. Weekly Compilation of Presidential Documents, $36,2868-2869$.

Cummings, P.H. (1998). Nursing in Barbados: A fourth-year elective practice experience for nursing students and registered nurses. Journal of Nursing Education, 37, 42-44.

Davis, T.M. (1999). Open doors: Report on international education exchange. New York: Institute of International Education.

Duffy, M.E. (2001). A critique of cultural education in nursing. Journal of Advanced Nursing, 36, 487-495.

Duffy, M.E., Harju, L., Huittinen, L., \& Trayner, C. (1999). An innovative model for international undergraduate education. Nursing and Health Care Perspectives, 20(1), 26-31.

Gallicchio, V.S., Kirk, P., \& Birch, N.J. (1998). Use of an international faculty/student exchange program as a process to establish and improve graduate education and research within an allied health discipline. Journal of Allied Health, 27(1), 31-34.

Goldberg, L.K., \& Brancato, V.C. (1998). International education: A United Kingdom nursing student partnership. Nurse Educator, 23(5), 30-34.

Grady, M.P. (1998). Qualitative and action research: A practitioner handbook. Bloomington, IN: Phi Delta Kappa Educational Foundation.

Haloburdo, E.P., \& Thompson, M.A. (1998). A comparison of international learning experiences for baccalaureate nursing students: Developed and developing countries. Journal of Nursing Education, 37, 13-21.

Hannerz, U. (1996). Transnational connections: Culture, people, places. New York: Routledge.
Heller, B., Oros, M., \& Durney-Crowley, J. (2000). The future of nursing education: Ten trends to watch. Retrieved January 9 , 2002, from the National League for Nursing Web site: http://www.nln.org/nlnjournal/infotrends.htm

Inglis, A., Rolls, C., \& Kristy, S. (1998). The impact of participation in a study abroad program on students' conceptual understanding of community health nursing in a developing country. Journal of Advanced Nursing, 28, 911-917.

Iwasiw, C., Andrusyszyn, M.A., Moen, A., Ostbye, T., Davie, L., Stovring, T., et al. (2000). Graduate education in nursing leadership through distance technologies: The CanadaNorway nursing connection. Journal of Nursing Education, $39,81-86$

Kim, Y.S., \& Vetter, R. (1999). An international distance learning nursing course in the U.S. and Japan. Journal of Cultural Diversity, 6(2), 48-56.

Kirkpatrick, M.K., \& Brown, S. (1999). Efficacy of an international exchange via the internet. Journal of Nursing Education, 38, 278-281.

Kraemer, L.G. (1998). Transatlantic cooperation: Using a consortial approach to enhance health professions education and practice. Journal of Allied Health, 27(1), 19-23.

Kumpfer, K.L., \& Hopkins, R. (1993). Prevention: Current research and trends. Psychiatric Clinics of North America, 16(1), 11-20.

Kumpfer, K.L., Turner, C., Hopkins, R., \& Librett, J. (1993). Leadership and team effectiveness in community coalitions for the prevention of alcohol and other drug abuse. In R.M. Goodman, J.N. Burdine, E. Meehan, \& K.R. McLeroy (Eds.), Health education research: Community coalitions for health promotion (pp. 354-374). Oxford, UK: Oxford University Press.

McNiff, J., Lomax, P., \& Whitehead, J. (1996). You and your action research project. London, UK: Hyde.

Mills, G.E. (2000). Action research: A guide for the teacher researcher. Upper Saddle River, NJ: Prentice-Hall.

Mohr, W.K., \& Naylor, M.D. (1999). Breaking through the hegemony of homogeneity. Revitalizing curriculum and students. Journal of Nursing Education, 38, 28-32.

Peterson, P.M. (2000). The worthy goal of a worldly faculty. AAC\&U Peer Review, 3(1), 13-17.

Rolls, C., Inglis, A., \& Kristy, S. (1997). Study abroad programs: Creating awareness of and changing attitudes to nursing, health and ways of living in other cultures. Contemporary Nursing, 6, 152-156.

Ryan, D., Markowski, K., Ura, D., \& Liu-Chiang, C. (1998). International nursing education: Challenges and strategies for success. Journal of Professional Nursing, 14, 69-71.

Scully, J., Birchfield, M., \& Munro, L. (1998). An international nursing course: The health system, England. Nursing \& Health Care, 19, 208-213.

Stevens, G.L. (1998). Experience the culture. Journal of Nursing Education, 37, 30-33.

Wheeler, D.L. (2000). More students study abroad, but their stays are shorter. Chronicle of Higher Education, 47(17), 74.

Zorn, C.R., Ponick, D.A., \& Peck, S.D. (1995). An analysis of the impact of participation in an international study program on the cognitive development of senior baccalaureate nursing students. Journal of Nursing Education, 34, 67-70. 
Copyright of Journal of Nursing Education is the property of SLACK Incorporated and its content may not be copied or emailed to multiple sites or posted to a listserv without the copyright holder's express written permission. However, users may print, download, or email articles for individual use. 